\title{
Reassessing the capacities of entertainment structures in the Roman Empire
}

Article

Accepted Version

Hanson, J. and Ortman, S. (2020) Reassessing the capacities of entertainment structures in the Roman Empire. American Journal of Archaeology, 124 (3). pp. 417-440. ISSN 0002-9114 doi: https://doi.org/10.3764/aja.124.3.0417 Available at https://centaur.reading.ac.uk/90667/

It is advisable to refer to the publisher's version if you intend to cite from the work. See Guidance on citing.

To link to this article DOI: http://dx.doi.org/10.3764/aja.124.3.0417

Publisher: Archaeological Institute of America

All outputs in CentAUR are protected by Intellectual Property Rights law, including copyright law. Copyright and IPR is retained by the creators or other copyright holders. Terms and conditions for use of this material are defined in the End User Agreement.

$\underline{\text { www.reading.ac.uk/centaur }}$

\section{CentAUR}


Central Archive at the University of Reading

Reading's research outputs online 
Reassessing the capacities of entertainment structures in the Roman Empire

$<\mathrm{A}>$ Abstract

In recent years, scholars have become increasingly skeptical of the idea that there is any relationship between the capacities of entertainment structures such as theaters and amphitheaters and the populations of Graeco-Roman cities. In this article, we begin by offering a model of information percolation in cities grounded in settlement scaling theory. We then show that, although there is a systematic relationship between the capacities of both theaters and amphitheaters and the populations of cities in the Roman Empire, this relationship is far from linear, indicating that a decreasing fraction of the population attended events in entertainment structures. In addition, although there is a great deal of variation in the extent to which each site conforms to the underlying relationships, there is a strong pattern in the sizes of these deviations and the overall standing of sites, as reflected in their civic statuses. Collecting similar measures for other relationships might be a useful way of characterizing sites and indicates a fruitful avenue for future research.

\section{$<\mathrm{A}>$ Introduction}

Despite initial enthusiasm about using the numbers of seats in entertainment structures, such as theaters, amphitheaters, and (less often) circuses, as a proxy for the number of residents in Graeco-Roman cities, there has been increasing skepticism over the past fifty years about whether there is any relationship between the capacities of these structures and the populations of 
the sites in which they are found. ${ }^{1}$ This skepticism revolves around two main issues. The first is the association of entertainment structures with competition among and between elites. ${ }^{2}$ This is often discussed in the context of the dependence of Graeco-Roman cities on civic munificence, i.e., a cycle of activities that enabled elites to generate public approval by contributing their wealth to the public good through, for example, the construction of public buildings and the provision of the lavish spectacles that took place in and around them. ${ }^{3}$ An entertainment structure might be sized to display the donor's wealth and status rather than scaled to civic needs. This munificence is demonstrated both by epigraphic material, which highlights the importance of offering entertainment in the careers of the elite, and by the actual seating arrangements of theaters and amphitheaters, where the best seats were often reserved for officials, dignitaries, and other important visitors. ${ }^{4}$ The second issue is the likelihood that at least some of the spectators who filled these structures came from elsewhere. ${ }^{5}$ Such a situation is famously described by Tacitus, who reports a riot between the residents of Pompeii and visitors from Nuceria in 59 C.E. at a gladiatorial show; this riot eventually resulted in a senatorial ban of such events for ten years, but similar incidents are known to have occurred elsewhere. ${ }^{6}$ Additional support for this interpretation comes from nearly one hundred notices on the walls of Pompeii (the so-called edicta munerum), which advertise a regular calendar of events, presumably reflecting the efforts of their sponsors to attract the largest crowds possible. ${ }^{7}$ The most striking aspect of these notices is that, although most relate to events in Pompeii, some refer to events in neighboring settlements (such as Nola, Nuceria, and Herculaneum) and slightly more distant places (such as Puteoli, Cumae, Cales, Capua, and Forum Popili) (table 1 and figure 1). As a result, it is not clear whether the capacities of entertainment structures reflect competition among elites (and therefore the wealth and status of the site), the numbers of spectators that could have come from elsewhere 
(and therefore the sizes of the catchments and overall social and economic influence of sites), or both. It is for these reasons that scholars have had difficulties using the capacities of entertainment structures to estimate the populations of ancient cities.

We believe the time is ripe to reassess the links between the capacities of entertainment structures and urban populations for two reasons. First, there is increasing evidence for systematic relationships between the sizes of settlements and their infrastructure in both ancient and modern contexts. ${ }^{8}$ For example, recent work has demonstrated consistent relationships between the populations of Graeco-Roman cities and the dimensions of mixing spaces, such as fora and agorae, and street networks. ${ }^{9}$ An important question is therefore whether such relationships can also be detected for entertainment structures. Second, an important consequence of recent work has been the development of independent estimates of the populations of sites, based on the sizes of their inhabited areas and residential densities. ${ }^{10}$ Although these figures are approximate, they do nonetheless allow one to look at the overall relationships between the sizes of sites and the capacities of entertainment structures for the first time.

Here, we combine existing measurements of the capacities of entertainment structures with recent population estimates to examine the relationships between them, allowing us to shed new light on the functions of these structures. We also examine the extent to which deviations of individual cities from the average relationship between population and structure capacity reflect 
local differences among sites, such as variation in the wealth and status of sites or the populations of neighboring settlements.

This article is grounded in an approach that has come to be known as settlement scaling theory. ${ }^{11}$ This approach views human settlements as built environments that facilitate interactions among individuals in space and time and so lead to systematic relationships between the populations of settlements and various elements of their built environments. We use this approach to investigate the extent to which the capacities of entertainment structures are related to the populations of cities and to assess the degree to which other factors might have influenced these capacities. We begin by offering an abstract model for how entertainment structures in Graeco-Roman cities might have functioned, which is based on recent work in complex systems concerning the percolation of information through social networks. ${ }^{12}$ We then describe how we have arrived at estimates of the numbers of residents in settlements and the numbers of seats in entertainment structures before discussing their relationship.

We will show that there is indeed a systematic relationship between the populations of sites and the capacities of both theaters and amphitheaters. This relationship is not linear, however, meaning that the sizes of sites tend to grow much faster than the capacities of entertainment structures. On average, a smaller fraction of urban residents would have been able to attend events in entertainment structures in larger cities than was the case in smaller cities. A striking feature of our results is that the data for individual cities can deviate substantially from the overall average relationship (i.e., they can exhibit large residuals from the best-fit line, that is the 
line that best describes the relationship between the capacities of entertainment structures and the populations of cities). We therefore investigate whether some of this variation can be accounted for using other properties of individual sites. Although our results are only preliminary, they suggest that deviations from the average relationship are correlated with civic status. These deviations indicate that the more important sites were more likely to have had a larger theater or amphitheater than we would expect based only on their size. Additional scale-adjusted urban indicators of this kind might be useful for a variety of purposes when the data are of sufficient quality.

$<$ A $>$ Information flow in ancient cities

There is now a wide range of scholarship that highlights the importance of information percolation for the development of human settlements and regards the generation of shared experiences and knowledge through collective events as a key dimension of social cohesion. ${ }^{13}$ In this context, although most ancient cities were too large to have relied on continuous face-to-face interaction to maintain social cohesion, they were still small enough that they would not have needed to rely on the kinds of broadcast media that are used for this purpose in the modern world. ${ }^{14}$ As a result, we would expect one of the social technologies developed by ancient societies to facilitate social cohesion to have been collective events that involved a sufficiently large fraction of the community that any information conveyed through the event could percolate, or be readily disseminated, through the rest of the social network. ${ }^{15}$ In this section, we provide a formal model for how the experience of attending an event, and any other information that was conveyed by that event, could have been disseminated from an initial group of witnesses to the rest of the community. 
Our model is based on the idea that information is one of the most fundamental quantities that flows through social networks. The percolation of information through a social network is determined by a combination of the number of people who receive such visual or auditory information and their ability to pass on this information to others. A model for the percolation of information through a social network can therefore be based on three simple variables: the number of people who originally witnessed an event, the average number of social contacts that each individual has (known as the average degree), and the number of times we would expect the news to be transmitted from individual to individual (known as the path length). It is then a simple enough task to put this into mathematical form, beginning with an initial number of witnesses and considering how many average social contacts would be necessary and how many times information would have to be transmitted for the associated social information to spread throughout the community. It is important to point out that we would not necessarily expect these social networks to be confined to the immediate residents of cities, since they could also include anyone who regularly interacted with others in the context of the built environment, in keeping with how modern settlements are treated.

A variety of evidence supports the view that the average social connectivity of individuals increases proportionately to settlement population density and that density increases with settlement population. ${ }^{16}$ Given this, a decreasing fraction of the urban population will need to be exposed directly to a message for it to be disseminated to the entire population in a given number of steps. The size of this necessary fraction can be computed by considering the total number of 
people who receive the message at a given number of degrees of separation from the original witnesses. This is given by the final term of the geometric series:

$$
N_{r}=N_{w} k_{w}{ }^{h},
$$

where $N_{r}$ is the total number of people who receive the message, $N_{w}$ is the number of witnesses, $k_{w}$ is the average number of social contacts of each witness (i.e. the degree centrality), and $h$ is the average path length, or the number of social intermediaries, through which the news travels (i.e., the network distance).

Next, we can represent the fraction of inhabitants of a city of size $N$ who were eye-witnesses to events in entertainment structures as $N_{w}=N^{\beta}$, with $\beta<1$, and the average connections of the witnesses as $k_{w}=k_{0} N^{\delta}$, where $k_{0}$ is the baseline number of social contacts, $N$ is the population, and $\delta$ is an exponent, based on recent theoretical and empirical work. This allows us to specify the relationship between the numbers of people who received a message and the numbers of eyewitnesses by substituting these relationships into equation 1 , as follows:

$$
N_{r}=k_{0} N^{\beta+h \delta} .
$$

If we further assume that every individual eventually receives the message, the value of $k_{0}$ and the exponent $\beta+h \delta$ both become equal to one, leading to $N_{r}=N$. In addition, we would expect the average connectivity between individuals to increase proportionately with the population density, such that the value of $\delta$ can be determined by specifying how the densities of settlements change with the size of their inhabited areas. Based on earlier work, we can write: $A=a N^{1-\delta}$, which can be re-arranged to solve for population $N$ as follows: 


$$
N=(1 / a)^{1 / 1-\delta} A^{1 / 1-\delta}
$$

and then to solve for the population density $D$ as follows:

$$
D=N / A=(1 / a)^{1 / 1-\delta} A^{-1 / 1-\delta} \cdot 17
$$

As we have shown elsewhere, since the value of $\delta$ is about 1/3 for Graeco-Roman cities, the average social connectivity of individuals should increase with the urban population raised to the $\delta=1 / 3$ power. ${ }^{18}$ As a result, if residents sought to create built environments in which everyone could receive the information conveyed at public events second-hand (i.e., directly from eyewitnesses, such that $h=1$ ), we would expect the capacities of entertainment structures to increase with population raised to the $\beta=2 / 3$ power. But, if the information could be obtained third-hand $(h=2)$, the capacities of entertainment structures would only need to increase with population raised to the $\beta=1 / 3$ power. Notice also that, as the information comes to be obtained fourth-hand ( $h \rightarrow 3$ ), the exponent $\beta \rightarrow 0$, meaning that the fraction of the population exposed to the information can approach a constant that does not change with city size. However, it is also important to recognize that information degrades with each link in the chain of transmission. This implies that the quality of the information conveyed will also degrade with $h$. We suggest that third-hand accounts represent the practical limit for conveying the details of a specific event to others with sufficient fidelity to be of much use. Thus, we consider $h=2$ to be an upper limit.

Although these equations might initially seem quite daunting, they simply propose that the flow of social information within a settlement is set by the number of eye-witnesses, the number of people each person regularly interacts with, and the number of times a piece of information is 
transmitted from person to person. In other words, the smaller the initial number of eyewitnesses, the larger the number of people through whom the information has to pass if the information is to reach the entire settlement. This model allows us to imagine a number of scenarios for how many people would have to experience an event, how many people they would have to tell about it, how many times the information would have to be repeated for the news to spread throughout the community, and how these factors would have changed as cities increased in size. More specifically, these models suggest that we would expect there to be a linear relationship between the capacities of entertainment structures and the sizes of sites if everyone was expected to witness an event (i.e., with a slope, $\beta$, of 1), but an increasing sub-linear relationship (i.e., for the capacities of entertainment structures to increase at a slower rate than the size of the sites) if some of the community heard about the event second hand $(\beta=2 / 3)$ or even third hand $(\beta=1 / 3)$, reaching a practical limit after that $(\beta=0)$. These patterns are illustrated in table 2.

At this stage, we should add a few comments on what we mean by social information. In the context of the entertainment structures discussed in this article, we would expect most of the information that was shared by spectators to have been about the events staged in these structures, including the quality of the performances, the results of contests, audience reactions, who participated in or sponsored the events, which important people attended, the content of announcements, and any interpretations of their sociopolitical significance. It should be acknowledged, though, that the architecture of theaters and amphitheaters conveyed messages in its own right and that these structures were also prominent locations for setting up inscriptions, 
writing graffiti, or sharing gossip. Here, we only focus on the former category of social information, that related to the events themselves.

It is important to stress that our model does not require that people were aware of the formal relationships among community size, social connectivity, and information that we have specified above. We do, however, suggest that architects had a shared sense of the socio-political potential of theaters and amphitheaters and made a mental calculation of how large they needed to be to meet the perceived needs of the local community. Although we would not expect architects to have designed these structures for the express purpose of fostering social cohesion, it is widely accepted that both theaters and amphitheaters were designed to reinforce elite authority through displays of generosity and to appease the masses, as is reflected in the persistent use of the phrase 'bread and circuses' to refer to the generation of public approval through diversions. It is therefore reasonable to view entertainment structures as having had an important role in fostering social cohesion.

We also stress that our model merely specifies the average relationship between entertainment structures and urban populations, as there are additional factors contingent upon local geographical or historical conditions that also influenced entertainment structure capacities in any given city. Thus, one can think of this model as providing a means of controlling for the effects of scale with regard to the social function of entertainment structures. When this is done, the degree to which the data for a given city deviates from the average relationship (known in regression analysis as the residual) becomes a scale-adjusted urban indicator (that is, an 
indication of how much a city deviates from the overall relationship, after taking its scale into account) that can be analyzed further to elucidate these additional factors. ${ }^{19}$

Finally, it should also be noted that this framework is dependent, at least in principle, on there being a direct correspondence between the capacities of entertainment structures and the sizes of sites at a given moment in time. Although most entertainment structures were probably built in response to urban growth, there were doubtless examples that fell short of or overcompensated for changing needs. As a result, there will inevitably be some mismatch between the capacities of entertainment structures and the populations of settlements. The best way to overcome these issues is to incorporate as many cases as possible into the analysis on the grounds that these errors will cancel each other out on average. Having said this, we would not expect these issues to affect the results very much, because we would expect to observe these errors in the deviations away from the underlying relationship, rather than in the overall nature of the relationship itself (since there is an equal chance of using evidence that is either too early or too late). These deviations should also be relatively minor, because we would not anticipate sites to have grown quickly enough to make very much difference to the results.

$<$ A $>$ Definitions, focus, and limits

In this study, we use the database of cities created by Hanson in his study of the Roman world in the imperial period. ${ }^{20}$ To define cities, Hanson concentrated on sites that likely engaged in secondary and tertiary activities (i.e., manufacture, services, and trade) rather than primary ones (i.e., agriculture or mining), using the sizes of inhabited areas, occurrence of certain monuments, 
and documentation of civic statuses as proxies for these activities. We have also restricted our investigation to entertainment structures that were either built or rebuilt in the imperial period (i.e., between the first century B.C.E. and third century C.E.). This is the time when most theaters and amphitheaters were in use and is the period for which we have the most abundant evidence. Finally, we only focus on the theaters and amphitheaters associated with cities and towns, not those associated with sanctuaries or military sites.

$<\mathrm{A}>$ Inhabited areas, densities, and numbers of residents

Although various approaches have been suggested for estimating the populations of GraecoRoman settlements, the most common method involves measuring the extent of the inhabited area and then multiplying this by a range of population densities. ${ }^{21} \mathrm{We}$ follow the same approach here, again drawing on Hanson's catalogue, which includes estimates for the sizes of the inhabited areas of 885 sites based on a number of features, including the area enclosed by walls, the extents of urban grids, the sizes of residential zones, the situation of cemeteries, and the character of natural features such as changes in relief, rivers, and coastlines (these data are available online at: http://oxrep.classics.ox.ac.uk/databases/). ${ }^{22}$ We converted inhabited areas to population estimates using the relationship between the sizes and densities of sites derived in earlier work, based on the evidence for the number of residential units in the cleared portions of a sample of 50 sites from throughout the Graeco-Roman world, assuming an average of 5 persons per household (including men, women, children, and a small number of slaves). ${ }^{23}$ The latter figure is based on cross-cultural comparisons, supported by census material from Hellenistic and Roman Egypt. This evidence demonstrates that there is indeed a strong relationship between the inhabited areas and population densities of Graeco-Roman cities that is consistent with both 
theoretical and empirical work in a range of settings. ${ }^{24}$ Although this relationship can only be used as a guideline, it does allow us to estimate site populations independently of the capacities of theaters and amphitheaters, allowing us to examine the relationship between them in a consistent fashion for the first time. ${ }^{25}$

\section{$<$ A $>$ Entertainment structures}

The theaters and amphitheaters we consider in this article were venues for a wide range of activities, including dramas (ludi scaenici), recitals, lectures, gladiatorial fights and wild beast hunts (munera and venationes), circus acts, executions, and chariot races (ludi circenses), which were hugely popular (albeit to different degrees with different sections of the community). ${ }^{26}$ These were venues for collective events that played central roles in fostering social cohesion through the shared performance and observation of social, cultural, religious, and political activities, as well as through the expression of civic identity and loyalty to the imperial regime, identification of insiders and outsiders, and illustration of the consequences of falling out of line. ${ }^{27}$ In addition, most of the events staged in these structures were distinctive, largely unrepeatable events that carried significant meaning for those who witnessed them, enhancing the chances that they were discussed beyond their immediate context. This is borne out by graffiti from Pompeii and various other sites, which not only record the names of individual combatants but also the outcomes of specific contests (such as whether a gladiator was let off with his life or not), as well as by the existence of both glasses and lamps decorated with similar scenes of combat and the manufacture of statuettes that are often interpreted as souvenirs. For all these reasons, entertainment structures are appropriate for the theoretical approach developed above. 
It is important to think carefully about the design and function of these structures. Although theaters and amphitheaters can be regarded as venues in which individuals interacted, these interactions did not take the same form of social mixing as we have discussed elsewhere, where we concentrated on day-to-day encounters in the street or public spaces, rather than at collective events. ${ }^{28}$ Instead, the architecture of theaters and amphitheaters reflects a concern for social control, since audiences were rigorously segregated on the basis of class, gender, nationality, profession, and marital status. ${ }^{29}$ This is reflected in the design of these structures, which restricted access and facilitated the routing of spectators to the appropriate section of seating. ${ }^{30}$ In both theaters and amphitheaters, the cavea was often divided into five horizontal sections, known as maeniana, corresponding to hierarchical divisions of the community; namely the imperator and senatores, equites, plebs, women and children, and slaves. ${ }^{31}$ The seating arrangements of these structures thus reflected tightly defined groupings that encoded strong social divisions within the community. We do not regard this as problematic for the current argument because all who attended events in an entertainment structure received more or less the same social information and could subsequently share it with their social contacts (although what they focused on and how it was recounted would vary from person to person). Meanwhile, although there is some evidence that certain entertainment structures were initially built for the benefit of specific groups (say, citizens or colonists), there is less evidence for whether or not these distinctions were rigorously or continuously upheld.

In what follows, we focus on theaters and amphitheaters, the most common types of entertainment structures. There is some overlap in the design and function of these structures, so 
one should not assume that specific activities were necessarily restricted to one or the other. Although there are a few sites that contained both kinds of structures, most only had one or the other, so we have treated them separately in the sections below (there are only a few sites with more than one of each kind of structure).

To identify sites with entertainment structures, we draw once again on Hanson's catalogue, which incorporates information from a range of sources. ${ }^{32}$ These include Sear's Roman Theatres, which uses a mixture of literary, archaeological, and epigraphic evidence to provide a catalogue of all known theaters in the Roman world in the imperial period. ${ }^{33}$ This source contains about a thousand entries, including theaters and other buildings of a theatrical type such as odea, theateramphitheaters, and theater-sanctuaries, many of which are illustrated by architectural drawings. In addition, it includes information on overall dimensions, orchestra and cavea widths, orchestra and cavea areas, and occasionally seating capacities. Additional sources include Golvin's L'amphithéâtre romain (The Roman Amphitheater), which provides a catalogue of around two hundred amphitheaters in the Roman world in the imperial period, and Bomgardner's The Story of the Roman Amphitheater, which contains some updated information about Italy and North Africa. ${ }^{34}$ These sources also include such details as overall dimensions, the lengths and breadths of arenae and caveae, and the areas and capacities of arenae and caveae. Although there are other sources that we could have consulted (such as Heath's recent work on amphitheaters), these would have simply replicated the data in other sources. ${ }^{35}$ A final point is that, although these sources include a number of structures with irregular forms, such as the hybrid theateramphitheaters that were especially common in the northwest, there is also relatively limited evidence for them. ${ }^{36}$ Since we do not have enough cases to examine these structures by 
themselves and do not want to simply amalgamate them with theaters or amphitheaters, we have excluded these irregular forms from the analysis. Similarly, we do not have much information on the capacities of circuses and hippodromes, simply because they are relatively rare by the standards of theaters and amphitheaters and relatively little work has been done on them. ${ }^{37}$ For these reasons we limit the investigation here to theaters and amphitheaters.

Although earlier structures exist at some sites, we have only looked at theaters that were built or rebuilt during the imperial period unless there is evidence that they were modified during the same time-frame, such as through an extension or reduction in the size of the cavea and any concomitant changes in orchestra or stage buildings (there are examples of both kinds of changes). The same concern does not apply to amphitheaters, since they all date to the imperial period. There are a few cases in which we could record changes in the capacity of a theater or amphitheater over time. For the purposes of this this article we simply use the largest figure documented for the imperial period, so as to compare the peak capacities of entertainment structures with the peak populations of the settlements in which they occur. It should also be noted that a few theaters were converted in the imperial period by turning the orchestra into an arena, so they effectively had a dual use as both theaters and amphitheaters. ${ }^{38}$ We have marked these in the supporting materials but note that including or excluding them does not make a material difference in the results.

The most common method for estimating the capacities of entertainment structures involves simple formulae that approximate the shapes of both kinds of structures based on evidence for 
their basic dimensions, such as the overall lengths, breadths, and widths of their seating areas and event spaces. ${ }^{39}$ As Rose has shown, we can calculate the surface area of the cavea in a theater by treating it as a half annulus, which can be derived by subtracting the area of one semi-circle from the area of another semi-circle. This can be achieved with a simple formula: $\left(\left(\pi * r_{1}^{2}\right) \div 2\right)-$ $\left(\left(\pi * r_{2}{ }^{2}\right) \div 2\right)$, where $r_{1}$ is the radius of the exterior semi-circle (i.e. the whole structure) and $r_{2}$ is the radius of the interior semi-circle (i.e. the orchestra). ${ }^{40}$ This equation is not ideal since the cavea often extended more than 180 degrees around the orchestra (these are especially common in the Greek world). We have therefore visually identified such cases from the diagrams in Sear's catalogue and conducted the same analyses both with and without them. As we will see below, although this does account for some of the most severe outliers from the overall relationships, it does not make much difference to the average relationship (although we do acknowledge that measuring structures directly from maps and plans would be one way to improve our analysis in the future). In the meantime, we can calculate the surface area of the cavea in an amphitheater by treating it as a hollow oval and then using a similar method. This can be done using the formula: $((A \div 2) *(B \div 2) * \pi)-((a \div 2) *(b \div 2) * \pi)$, where $A$ and $B$ are the lengths and widths of the exterior oval (i.e. the whole structure) and $a$ and $b$ are the lengths and widths of the interior oval (i.e. the arena). ${ }^{41}$ This equation is also somewhat of a compromise, given that many amphitheaters were not perfect ovals. ${ }^{42}$ The effects of this are a little more difficult to assess, since there are no hard and fast rules for calculating the amount that each structure deviates from an oval from maps and plans, but the effects of this are generally not as pronounced as with theaters. Since Sear did not include estimates for the sizes of each cavea, we have used the equation above to estimate their seating areas. In contrast, given that this information is already provided in both Golvin and Bomgardner's catalogues, we have simply 
used their figures (which are based on the same strategy). As Rose has pointed out, these areas would have also included some space for access and services, such as entrances and exits, staircases, and circulation aisles. ${ }^{43}$ Although the exact area that was taken up by these would have varied from building to building, we have followed Rose and most other scholars in assuming that they would have taken up, on average, about $10 \%$ of the surface area in question and reduced the estimates of seating capacities accordingly. ${ }^{44}$

With these seating areas in hand, we then estimate the numbers of spectators by assuming that there was a certain amount of space per person. To do this, we follow Rose, who has offered a variety of estimates of the area per seat, which range from a minimum of $0.3 * 0.5 \mathrm{~m}$ per spectator (i.e. $0.15 \mathrm{~m}^{2}$ each), to a median of $0.4 * 0.7 \mathrm{~m}$ per spectator (i.e. $0.28 \mathrm{~m}^{2} \mathrm{each}$ ), and a maximum of $0.5 * 0.8 \mathrm{~m}$ per spectator (i.e. $0.4 \mathrm{~m}^{2}$ each). ${ }^{45}$ These are based on a combination of textual and archaeological evidence (such as Vitruvius's Ten Books on Architecture and markings on the seats of some structures) and contemporary guidelines for modern facilities. ${ }^{46}$ In particular, although Vitruvius recommends an average depth of 0.6 to $0.7 \mathrm{~m}$, he does not comment on the width, which is derived from remains at Arles and Pola. ${ }^{47}$ We have used the median seating area of $0.28 \mathrm{~m}^{2}$ to convert the estimates for seating areas of each structure into estimates of the numbers of spectators in each one. This figure can be applied to the entire group of theaters and amphitheaters discussed below, especially given that there is no evidence that seating areas in entertainment structures in larger sites were any more or less cramped than smaller ones. We should not set too much store in the absolute value of figures, given that even a small change in these parameters ( area that has been allowed per spectator and therefore on the estimates for the total capacities of 
these structures. ${ }^{48}$ This should not have any effect on the overall relationship across sites, however, since we have used the same conversion for the seating area per person for all sites (i.e. it is a constant in our calculations).

Our analysis assumes that both theaters and amphitheaters were usually filled to capacity and that most of the audience was seated rather than standing. There is no way to test these assumptions using the available evidence (although the amount of seating pressure might be detectable in the residuals to the overall relationship, as we will see below). It is important to point out, however, that, although we would expect both theaters and amphitheaters to have made important statements for their builders, we would not expect builders to have incurred any unnecessary expenditure in the construction of seating areas, if only because such funds could have been better spent on underwriting more impressive events or more lavish amenities for spectators. We also do not know how often events were staged, although we can assume that they occurred more often in larger sites.

It should also be remembered that the total number of people who interacted with these structures could have been a little higher than their seating capacities, since we know that individuals gathered outside as well as inside entertainment structures. For example, Tacitus refers to people who were attending the spectacle as well as people who were standing around the actual building as being caught up the collapse of the amphitheater at Fidenae in 27 C.E. ${ }^{49}$ Many of these structures had dedicated retail spaces on their outsides as well. Nevertheless, we 
would expect the numbers of non-seated individuals to have been small relative to the number of people inside.

In the case of the imperial capital, we have used Rose's figures for the seating areas of the Theatre of Marcellus and the Colosseum, which are 5,471 and 18,006 $\mathrm{m}^{2}$ respectively (minus access and service areas). These figures suggest these structures could have held 19,539 and 64,308 spectators respectively. ${ }^{50}$ We then added our own estimate for the Theatre of Pompey and the Theatre of Balbus, based on more recent work, which suggests a seating area of about 6,749 and 3,007 $\mathrm{m}^{2}$ for each one, indicating around 24,103 and 10,739 spectators. ${ }^{51}$ Although we are aware of the existence of several other amphitheaters at Rome, such as the Amphitheater of Statilius Taurus, Amphitheater of Caligula, and Amphitheater of Nero, it is usually assumed that these had either been demolished or had burnt down by the time of the construction of the Colosseum (the Ludus Magnus is usually regarded as a training school and the Amphitheatrum Castrense is a little later and was attached to an imperial residence), so we do not include these structures here. Although there are a couple of other sites with more than one theater or amphitheater, most only have one of each, meaning that we do not have to confront the sampling issues that would arise with more common or more abundant structures, such as temples, baths, etc.

$<\mathrm{A}>$ Investigating scale-adjusted variation

As we will see below, one of the advantages of the approach used in this article is that it allows one to control for the effects of scale, thus revealing the extent to which entertainment structures 
at specific sites are larger or smaller than expected, based on the population of their associated settlement. This scale-adjusted deviation from the average relationship is referred to as a residual. Although archaeologists have typically regarded residuals as a reflection of error, it is also possible to regard as them as a reflection of meaningful differences in the social and economic conditions at each site, which are therefore referred to as scale-adjusted urban indicators. ${ }^{52}$ We would expect such deviations to result from a range of factors that are not included in the theoretical model discussed above. In the context of entertainment structures, we might expect residuals to correlate with the overall wealth, status, and influence of sites. For example, we might expect the sites with the greatest wealth and status to have had theaters and amphitheaters that are larger than would be expected based on their population (i.e., the capacities of their entertainment structures exceeded the needs of their inhabitants).

To test this possibility, we examine correlations between residuals and other attributes of sites, of which the most important is a site's civic status. These data are derived from Hanson's catalogue, which includes most of the available information offered by standard sources. ${ }^{53}$ Civic statuses are notoriously complicated since they were never properly rationalized, were subject to constant negotiation, and were open to extensive abuse, but we can group them into four broad categories: the capital of the empire, provincial capitals, coloniae, and municipia. These categories are obviously a simplification of the range of civic statuses enjoyed by specific sites, but they are sufficient for our purpose, which is to offer a coarse-grained classification of the overall standing of each site that incorporates a variety of factors, such as its historical importance or its role in the administration of the empire. Since the status of cities changed over time, we have used the highest status attained by each city, on the assumption that this status 
should bear the closest resemblance to its estimated population, which is usually based on its maximum extent.

Next, we captured basic information about both the numbers of people living in neighboring cities and the carrying capacity of the hinterlands of each site. Although it is not possible to reconstruct these hinterlands in detail, we can estimate their extents using simple ring buffers representing one day's travel from the center of each site, on the grounds that we would not expect most spectators to have travelled for more than one day to reach an event. ${ }^{54}$ This distance can be based on modern handbooks, which suggest that an individual of average health and fitness can cover around $5 \mathrm{~km}$ in about an hour on foot, i.e. $40 \mathrm{~km}$ in eight hours. ${ }^{55}$ This figure is also supported by estimating the distance between Pompeii and the other sites in the advertisements for events referred to above, since most of them are within $40 \mathrm{~km}$ and the average distance from Pompeii is about $35 \mathrm{~km}$ (table 1 and figure 1). Although one could use costsurfaces to take account of differences in the landscape, such as elevation, rivers, and seas, that might make it easier or harder to traverse, such details should not make much difference to the results given the scale of our analysis.

The numbers of people living in neighboring cities has been calculated by simply summing the known estimated populations of the cities in each ring buffer. Although it is not possible to estimate the numbers of people living in rural areas based on current evidence, it is possible to use the natural endowment of the landscape as a rough index of the number of individuals who might have lived on the land. Here, we have used Galor and Özak’s caloric suitability indices, 
which give us an indication of how the total numbers of calories that could have been derived from each of the crops that were available for cultivation in the pre-1500 C.E. era varied from region to region (and therefore a rough indication of the relative numbers of individuals who could have been fed in a given area, i.e. their carrying capacities). ${ }^{56} \mathrm{We}$ combined this model with the ring buffers to calculate the average numbers of calories available to each site, giving us a crude sense of how much the average carrying capacity varied from site to site.

Finally, by considering the distances between sites and both seas and rivers as recorded in Hanson's catalogue (we have not included roads, since we would expect all the sites to be located at or near important intersections), we obtain a rough indication of how well-connected sites were, again taking this information from Hanson's catalogue. ${ }^{57}$

\section{$<$ A $>$ Results}

Of the 783 theaters and 330 amphitheaters known for the Graeco-Roman world, we have evidence for the capacities of 173 theaters and 107 amphitheaters (figures 2 and 3; for the full list see online appendix 1). ${ }^{58}$ These data derive from 238 sites distributed throughout the Roman world and dating from the imperial period with estimated populations ranging from under a thousand to almost a million inhabitants. 43 of these sites have both a theater and an amphitheater. 
We assess the relationship between the populations of cities and the capacities of their theaters and amphitheaters through standard regression techniques, as shown in table 3 and figures 4 and 5. ${ }^{59}$ We have also calculated the residual of the capacity for each city given the value predicted by each regression.

These results show that there is indeed a systematic relationship between the estimated populations of cities and the capacities of both theaters and amphitheaters. The slopes of the best-fit lines for these relationships (i.e. the lines that best describe the data) are almost identical to each other, exhibiting similar values of about one-third (in other words, the capacities of both theaters and amphitheaters increase at the same rate, but much slower than the population). In light of the theoretical discussion above, this result suggests that, in the average city, the social information conveyed through events in entertainment structures could have spread to the entire urban population through an average of two intermediaries $(h=2)$. This result is remarkable, given the wide range of factors one might have expected to affect the results. It is also worth noting that removing entertainment structures with irregular forms or that were modified in the imperial period makes no meaningful difference in the results (for example, removing theaters with non-semi-circular caveae yields an exponent of 0.338 , while removing the theaters that had been modified gives 0.358 (almost no change)). The results suggest that the structures in question might have had similar roles and that the overall relationship between city population and entertainment structure capacity was very robust.

$<\mathrm{A}>$ Discussion 
Although our analysis shows that the capacities of entertainment structures did increase as the populations of cities increased, this relationship was far from linear, meaning that the populations of sites tended to grow much faster than the capacities of their entertainment structures. This relationship implies that a smaller fraction of urban residents could have attended an event in an entertainment structure in larger cities (and this fraction decreases at a consistent rate across the full range of city sizes). It is also interesting to observe that there is a correlation between the capacities of theaters and amphitheaters in the small number of sites that had both kinds of structures; that is, a site with a relatively large theater usually has a relatively large amphitheater as well (Figure 6). There is a slight imbalance in this relationship, however, since the capacities of theaters increase slightly faster than the capacities of amphitheaters. As we will see below, although cities in the east are more likely to have had a theater, and those in the west an amphitheater, there is no significant difference in the extent to which cities in the east or west deviate from the theater-size and amphitheater-size relationships. Although the decision about whether to build a theater or amphitheater might have been culturally informed, any decisions about how large or small it should be are more likely to be a product of the specific needs of the community it was destined to serve.

Although it is important not to put too much faith in specific figures for specific sites, an interesting aspect of our results is that they suggest that the average capacities of theaters and amphitheaters were one or two times larger than their resident populations. Apparently, most entertainment structures were designed to accommodate both the residents of the cities in which they were located and visitors from elsewhere, in keeping with our expectations. ${ }^{60}$ It is also striking, however, that there is an inverse relationship between the populations of cities and the 
percentage of residents who could have been accommodated by both theaters and amphitheaters (figures 7 and 8). The capacities of entertainment structures in the smallest cities were often several times larger than their resident populations, while those in the largest cities were often several times smaller. Smaller sites might thus have been more likely to have provided for both themselves and their neighboring surroundings, while it would have been difficult for the largest sites to have provided for more than a fraction of their own communities. It is possible, therefore, that the function of entertainment structures changed somewhat as the size of the sites they are associated with increased. This observation gives us a new view of both theaters and amphitheaters that might help to resolve the uncertainties about their design and function referred to in the introduction. If true, it also raises the interesting possibility that at least some of this deficit might have been made up by putting on events more frequently in larger sites, in keeping with our sense that larger sites were more affluent. Regardless, the consistent slope of the relationships between population and entertainment structure capacities shows that the fraction of the overall social network of a city that could attend events in an entertainment structure decreased in a consistent way across cities of all sizes. Given this, an important question for future research is whether the sizes of the overall social networks (i.e. all those who regularly interacted with each other in cities, regardless of whether they dwelt within them) increased faster than, slower than, or at the same rate as, city populations. If the size of the social network increased faster than the population of the central city it would mean that the fraction of this social network that could attend events in entertainment structures would decrease even faster than we observe for the city itself in figures 4 and 5 (i.e., the slope of the best-fit lines would be less than 1/3); and if the size of the social network increased more slowly than the 
population of the central city it would imply that this fraction decreased less rapidly than observed (i.e. with a slope of more than 1/3).

The results are consistent with a model of information percolation in social networks in which the initial number of witnesses was a fraction of the city population given by $N^{\beta}$, with $\beta=1 / 3$, and with an average path length of $h=2$. In such a social network, everyone would have received the news in no worse than a second-hand account, and we can conclude that the social networks of these cities were sufficiently functional for information to have been disseminated throughout the community and that these communities were sufficiently connected to have maintained a sense of shared local identity. We also note that these results are consistent with contemporary real-world networks, including social networks, which are characterized by high clustering and small average path lengths (these networks are often called small worlds, after the likelihood that each person is linked to every other person through a small number of mutual acquaintances). Our results provide the first empirical evidence for an additional advantage of agglomeration, the enhanced percolation of information, leading to significant economies of scale in how information is disseminated in settlements. Plotting the relationship between the capacities of entertainment structures and the populations of sites also allows us to assess how much of the variation in one is accounted for by variation in the other, which in this case is over a third for both kinds of entertainment structure, indicating that additional factors beyond population size were involved in determining the capacities of entertainment structures in individual cities. Below, we examine some of these potential factors. 


\section{$<$ A $>$ Residuals}

As can be seen in Figures 4 and 5, individual sites rarely fall exactly on the best-fit line. Instead, the observed capacities for most sites are greater than or less than the expected value for their sizes and populations. This variation is represented by the residuals, that is, the vertical deviation from the best-fit line, for each site and structure type. These residuals reflect a range of factors, including not only error in the area and density estimates for sites (and therefore their population estimates) but also error in the estimated capacities of structures, not to mention slight mismatches in time between entertainment structure construction and peak urban population and any misjudgments by patrons and architects regarding current and future demand for entertainment space. Having said this, we would expect all of these errors to be independent of the sizes of sites (i.e. for them to be unstructured relative to site size), and, if so, there may be patterns in the residuals that reflect meaningful differences in local social and economic conditions. This seems to be borne out by the fact that, across sites containing both theaters and amphitheaters, the magnitude of the theater residual is correlated with the magnitude of the amphitheater residual (figure 9). This observation is consistent with the idea that a common set of factors determined the deviation of both kinds of entertainment structures from the average relationship. It is also encouraging that positive and negative residuals seem to cluster together in some areas, as seen in parts of both Gaul and North Africa, for example (figures 10 and 11).

Tables 4 and 5, and figures 12 and 13, summarize the magnitudes of the residuals for, respectively, the relationships between population and theater capacity and between population and amphitheater capacity in accordance with the highest civic status associated with each city. Although the results are not statistically significant, they are nonetheless strongly patterned, with 
more positive residuals generally being associated with higher-status sites. Specifically, provincial capitals have the largest positive average residuals for both theaters and amphitheaters, followed by increasingly negative average residuals for coloniae and municipia. This result is very much in line with our sense of the overall importance of these different classes of settlement in the administrative structure of the empire. In short, these patterns suggest that more important sites were more likely to have had larger theaters or amphitheaters than we would expect for a city of their size.

It is striking, however, that there is no relationship between the sizes of residuals and the other attributes described above, which suggests that there is no single explanation for the overall trend between the residuals and statuses of sites referred to above (table 6). There are clearly some sites that had a rich tradition of monumental construction and might have attracted more elite expenditure, other sites that were located in dense networks that might have attracted more visitors from elsewhere, and still other sites whose deviation is more difficult to understand (perhaps suggesting that our information about them is less than ideal). There also does not appear to be any special link between sites with forts and scaling residuals. Although we do not believe the magnitudes of individual residuals are meaningful, because of the various sources of error in our data, these analyses do suggest that there are patterns in the residuals across groups of sites that potentially reflect additional dimensions of the social and economic contexts of cities and their effects on the development of entertainment structures. 
Another interesting outcome of the residual analyses is that Rome is a positive outlier from the relationship between population and theater capacity but a negative outlier from the relationship between population and amphitheater capacity (as illustrated by the magnitude of the residuals, which are about 0.17 and -0.05 respectively). Even though Rome had by far the largest entertainment structures in the Empire, it may still have been somewhat underserved in terms of its amphitheater capacity. ${ }^{61}$ This raises the question of whether the size of this negative residual reflects some other restricting factor, such as visual and auditory limits. As Rose has shown, we can examine the effectiveness of entertainment structures by considering the abilities of spectators to see and hear events, based on a spectator's maximum viewing angle of 120 degrees, a distance of 60 to $90 \mathrm{~m}$, and a maximum listening distance of $42 \mathrm{~m}$ to the front, $30 \mathrm{~m}$ to the sides, and $17 \mathrm{~m}$ to the rear. ${ }^{62}$ These limits were approached by entertainment structures in the capital. This suggests that limits of human perception, rather than the limits of building materials or construction techniques, might have been a primary constraint on the capacities of these structures and therefore on the extent to which social information could be disseminated through entertainment structures in the absence of technological aids. ${ }^{63}$ This observation might in turn have implications for the maximum size of settlements that could be sustained as functional socio-economic and spatial organizations in pre-industrial settings before the advent of other ways of disseminating information, such as newspapers and other broadcast media. In this context, it may be significant to note that Rome, the capital, would not be surpassed in size by another city until London did so sometime between 1800 and 1850, around the same time that fundamental changes were starting to be made in forms of and access to entertainment, along with nascent forms of mass media. ${ }^{64}$ 
Finally, we note that Pompeii is also a significant outlier from the relationship between population and amphitheater capacity, with a large positive residual of 0.28 , an indication that it had a relatively large amphitheater for a city of its size. Pompeii's large amphitheater may reflect the evidence, discussed above, that the city attracted a large number of visitors from elsewhere, including Nuceria. Perhaps we should ask whether the kind of intercity rivalry described by Tacitus in the context of the Pompeian-Nucerian riot was normal for the Roman world (as assumed by most scholars) or whether we might better regard it as a relatively unusual consequence of the large numbers of visitors that could attend events at Pompeii.

Our results also highlight the flexibility of the overall relationships discussed above by demonstrating how much sites may vary while still conforming to the same underlying relationships. The variation might help to explain why there has been so much difficulty using the capacities of entertainment structures to estimate the populations of sites, since it suggests that, although there is a general relationship between them, there is enough variation that using entertainment structures to estimate the population of sites is not reliable. At the same time, these results underscore the potential of using the deviations from the overall relationships as a reflection of the different dimensions of the sites.

\section{$<\mathrm{A}>$ Conclusions}

In this article, we have argued that one can think of human settlements as built environments that, in addition to facilitating the flow of goods and services, also facilitate the percolation of social information. This view leads to a model concerning the expected capacities of structures 
devoted to public entertainment. The model suggests that, as the population of a site increases, the fraction of the population that attends such events can decline, with no loss of functionality, because of the increasing connectivity of individuals in larger and denser settlements. We have tested this model using estimates of the sizes of the populations and the capacities of entertainment structures at several hundred Graeco-Roman cities and shown that there is indeed a systematic overall relationship between these urban indicators. Specifically, we find that the capacities of entertainment structures were sufficient, on average, for the social information conveyed at a public entertainment to reach the whole urban population through first-hand accounts of attendees and second-hand accounts of those informed by attendees. This result suggests that, in Graeco-Roman cities, there were sufficiently connected social networks to sustain the percolation of social information from eyewitnesses to the rest of the community.

We have also argued that we can use the extent to which each site deviates from these overall relationships as a reflection of its unique social and economic conditions (which we call scaleadjusted urban indicators), and we have examined a variety of factors that might be expected to have influenced the deviation of these structures from their expected values. Our results, although preliminary, indicate that there is a suggestive pattern in the scale-adjusted entertainment structure capacities and the overall standing of sites as reflected in their civic statuses. We believe that, when the data are of sufficient quality, the residuals of scaling relationships can be used to reveal variation in social and economic conditions after taking the effects of population size into account. 
Future work could expand on these results in a number of ways. First, investigators could seek to stratify the data into time periods and/or regional groups to investigate how deviations from the underlying scaling relationships varied over time or across space. Second, investigators could examine additional factors we have not considered to account for patterns in the residuals of the relationship between population and structure capacity. Third, investigators could further improve our ability to estimate the populations of Graeco-Roman cities by incorporating multiple scaling relationships (area, residential density, entertainment structure capacity, forum / agora area) into the estimation process.

Dr J. W. Hanson (University of Reading), j.w.hanson@ reading.ac.uk, Department of Classics, University of Reading, Reading, Berkshire, UK, RG6 6AA.

Professor S. G. Ortman (University of Colorado), scott.ortman @ colorado.edu, Department of Anthropology, University of Colorado, Boulder, Colorado, USA, 80302.

\section{$<$ A $>$ Table Captions}

Table 1. The sites advertised in notices from Pompeii (based on the list given in Carter and Edmondson 2014, 545).

Table 2. The range of possible values that will result in the spread of information from an initial group of witnesses to the rest of the community, as predicted by the model proposed in this 
article. This model takes the form $N_{r}=k_{0} N^{\beta+h \delta}$, where $N_{r}$ is the number of people who receive the message, $N^{\beta}$ is the fraction of the population who witness an event, $h$ is how many times the information will have to be repeated from person to person, and $\delta$ is the average number of social contacts that each person has. For information to spread across the whole settlement, $\beta+h \delta$ must equal one. As a result, the smaller the exponent for the initial number of eye-witnesses, the larger the number of people through whom the information has to pass if the information is to reach the entire settlement.

Table 3. The results of regressing the capacities of both theaters and amphitheaters against the estimated populations of sites. The independent variable is the estimated population in all cases, while the dependent variable is the capacities of either theaters or amphitheaters. This procedure allows us to estimate the slope of the relationship (the exponent) and a baseline amount for each kind of structure (the pre-factor), along with confidence intervals, a measure of how much variation in one variable is accounted for by variation in the other (the $\mathrm{R}^{2}$ ), and an index of their statistical significance (the $\mathrm{p}$-value). Despite the modest $\mathrm{R}^{2}$ values, all regressions are significant at the $\mathrm{P}<.0001$ level. Note that exponents of the relationships between the capacities of entertainment structures and estimated populations for sites are almost identical for both theaters and amphitheaters.

Table 4. The average deviation from the theater-population relationship (residuals), by civic status. Note the difference between the figures for provincial capitals, which are positive, and municipia, which are negative. 
Table 5. The average deviation from the amphitheater-population relationship (residuals), by civic status. Note the difference between the figures for provincial capitals, which are positive, and municipia, which are negative.

Table 6 . The results of regressing the residuals for both the theater-population and amphitheaterpopulation relationships against various attributes of cities (above: theaters; below:

amphitheaters). The independent variables include the estimated populations of neighboring cities, the total carrying capacities (calorific suitability index), and the distances to harbors and rivers (both in $\mathrm{km}$ ), while the dependent variables are the residuals. There is no relationship between them, suggesting that these attributes do not account for the magnitude of the residuals.

\section{$<$ A $>$ Figure Captions}

Figure 1. A map of the sites advertised in notices from Pompeii (based on the list given in Carter and Edmondson 2014, 545).

Figure 2. Locations of the theaters investigated in this study. Symbols are proportional to the seating capacities (in number of persons) of the structures.

Figure 3. Locations of the amphitheaters investigated in this study. Symbols are proportional to the seating capacities (in number of persons) of the structures. 
Figure 4. The relationship between the estimated populations of sites and the estimated capacities of theaters (in persons). The capacities are derived by measuring the amount of space given over to seating in each structure, divided by an estimated amount of space per person. The equation of the best-fit line is shown in the inset, where $\mathrm{y}$ is the capacity of the theater in question, $\mathrm{x}$ is the population of the site, and the numerals are the y-intercept and the exponent of the relationship. The $\mathrm{R}^{2}$ is a measure of how much variation in the capacities of theaters is accounted for by variation in the populations of sites. Both scales are logarithmic. This exercise reveals that, although there is a consistent relationship between these variables, it is not linear, meaning that the capacities of theaters increase much more slowly than the populations of sites.

Figure 5. The relationship between the estimated populations of sites and the estimated capacities of amphitheaters (in persons). The capacities are derived by measuring the amount of space given over to seating in each structure, divided by an estimated amount of space per person. The equation of the best-fit line is shown in the inset, where y is the capacity of the amphitheater in question, $\mathrm{x}$ is the population of the site, and the numerals are the $\mathrm{y}$-intercept and the exponent of the relationship. The value of the $\mathrm{R}^{2}$ is a measure of how much variation in the capacities of amphitheaters is accounted for by variation in the populations of sites. Both scales are logarithmic. As with theaters, although there is a consistent relationship between these variables, it is not linear, meaning that the capacities of amphitheaters increase much more slowly than the populations of sites. 
Figure 6 . The correlation between the estimated capacities of theaters and amphitheaters at sites with both kinds of structures. The equation of the best-fit line is shown in the inset. Both scales are logarithmic. Note that increasing theater size is generally accompanied by increasing amphitheater size.

Figure 7. The relationship between the estimated populations of sites and the percentages of the population served by theaters (these percentages are generated by dividing the same capacities as shown in figure 4 by the estimated population of each site, multiplied by 100). The equation of the best-fit line is shown in the inset. Both scales are logarithmic. Note that the capacities of theaters associated with smaller sites are often several times larger than the population, while those in larger sites are often a fraction of it.

Figure 8 . The relationship between the estimated populations of sites and the percentages of the population served by amphitheaters (these percentages are generated by dividing the same capacities as shown in figure 5 by the estimated population of each site, multiplied by 100). The equation of the best-fit line is shown in the inset. Both scales are logarithmic. Note that the capacities of amphitheaters associated with smaller sites are often several times larger than the population, while those in larger sites are often a fraction of it. Theaters show the same relationship (see fig. 7).

Figure 9. The correlation among the deviations of sites from the theater-size and amphitheatersize relationships (residuals) shown in figures 4 and 5, focusing on sites with both types of 
structures. These values are derived by measuring the extent of the deviation of each site from the best-fit line, with the magnitude of the deviation of each site from the theater-size relationship on the $\mathrm{x}$-axis and that from the amphitheater-size relationship on the $y$-axis. The results of regressing these variables are shown in the inset equation. This exercise shows that there is a relationship between the two sets of residuals, which suggests that the sites that are more likely to have a larger theater than we would expect for their size are also likely to have a larger amphitheater than we would expect, again for their size.

Figure 10. The deviation of sites from the expected relationship between the capacity of the theater at a site and the size of its population (residuals). Green arrows indicate positive residuals; red arrows indicate negative residuals.

Figure 11. The deviation of sites from the expected relationship between the capacity of the amphitheater at a site and the size of its population (residuals). Green arrows indicate positive residuals; red arrows indicate negative residuals.

Figure 12. The deviations of sites from the relationship between theater capacity and population size (residuals). Each bar is color-coded by civic status. Note that the residuals of provincial capitals are more often positive, while the residuals of municipia are more often negative. 
Figure 13. The deviations of sites from the relationship between amphitheater capacity and population size (residuals). Each bar is color-coded by civic status. Note that the residuals of provincial capitals are more often positive, while the residuals of municipia are more often negative. A similar effect is seen in theaters (see fig. 12).

$<$ A $>$ Works Cited

Auguet, R. 1972. Cruelty and Civilization: The Roman games. London: Allen and Unwin.

Bairoch, P. 1988. Cities and Economic Development: From the dawn of history to the present. London: Mansell.

Beacham, R.C. 1991. The Roman Theatre and its Audience. London and New York: Routledge. 1999. Spectacle Entertainments of Early Imperial Rome. New Haven: Yale University Press.

Benario, H.W. 1981. “Amphitheaters of the Roman world”. The Classical Journal 76.3:255-58.

Bettencourt, L.M.A. 2013. "The origins of scaling in cities". Science 340:1438-41. 
2014. "Impact of changing technology on the evolution of complex informational networks". Proceedings of the IEEE 102.12:1878-91.

Bettencourt, L.M.A., J. Lobo, D. Helbing, C. Kuhnert, and G.B. West. 2007. “Growth, innovation, scaling, and the pace of life in cities". Proceedings of the National Academy of Sciences 104:7301-6.

Bettencourt, L.M.A., J. Lobo, D. Strumsky, and G.B. West. 2010. "Urban scaling and its deviations: Revealing the structure of wealth, innovation, and crime across cities". PLoS One 5.11. e13541.

Bomgardner, D.L. 2000. The Story of the Roman Amphitheater. London and New York: Routledge.

Bowser, B.J., and J.Q. Patton. 2004. "Domestic spaces as public places: An ethnoarchaeological case study of houses, gender, and politics in the Ecuadorian Amazon”. Journal of Archaeological Method and Theory 11.2:157-81. 
Canuto, M.A., and J. Yaeger. 2000. The Archaeology of Communities: A New World perspective. London and New York: Routledge.

Carandini, A., P. Carafa, and A. Campbell Halavais. 2017. The Atlas of Ancient Rome:

Biography and portraits of the city. Princeton: Princeton University Press.

Carter, M.J., and J. Edmondson. 2014. "Spectacle in Rome, Italy, and the provinces". In The Oxford Handbook of Roman Epigraphy, edited by C. Bruun, and J. Edmondson, 537-58. Oxford: Oxford University Press.

Conolly, J., and M. Lake. 2006. Geographical Information Systems in Archaeology. Cambridge: Cambridge University Press.

de Ligt, L. 2012. Peasants, Citizens, and Soldiers: Studies in the demographic history of Roman Italy, 225 BC-AD 100. Cambridge: Cambridge University Press.

Duncan-Jones, R.P. 1982. The economy of the Roman Empire: Quantitative studies. Cambridge: Cambridge University Press. 
Fagan, G.G. 2011. The Lure of the Arena: Social psychology and the crowd at the roman games. Cambridge: Cambridge University Press.

Flohr, M. 2017. "Quantifying Pompeii: Population, inequality, and the urban economy”. In The Economy of Pompeii, edited by M. Flohr, and A.I. Wilson, 56-84. Oxford: Oxford University Press.

Frank, T.E. ed. 1938. An Economic Survey of Ancient Rome. Baltimore: Johns Hopkins University Press. Volumes I to VI.

Gagliardo, M.C., and J.E. Packer. 2006. "A new look at Pompey’s Theater: History, documentation, and recent excavation". American Journal of Archaeology 110.1:93-122.

Galor, O., and Ö. Özak. 2015. "Land productivity and economic development: Caloric suitability vs. agricultural suitability”. Brown University Working Paper.

2016. "The agricultural origins of time preference". American Economic Review

106.10:3064-103. 
Galor, O., Ö. Özak, and A. Sarid. 2016. “Geographical origins and economic consequences of language structures". Brown University Working Paper.

Golvin, J.-C. 1988. L'amphitheatre romain: Essai sur la theorisation de sa forme et de ses fonctions. Paris: Diffusion de Boccard.

Gros, P. 1996. L'architecture romaine: du début du IIIe siècle av. J.-C. à la fin du Haut-Empire. Paris: Picard. Volume I.

Hansen, M.H. 2006. The Shotgun Method: The demography of the ancient Greek city-state culture. Columbia: University of Missouri Press.

Hanson, J.W. 2016. An Urban Geography of the Roman World, 100 BC to AD 300. Oxford: Archaeopress.

Hanson, J.W., and S.G. Ortman. 2017. "A systematic method for estimating the populations of Greek and Roman settlements". Journal of Roman Archaeology 30:301-24.

Hanson, J.W., S.G. Ortman, L.M.A. Bettencourt, and L.C. Mazur. 2019. "Urban form, infrastructure, and spatial organization in the Roman Empire". Antiquity 93.369:702-18. 
Hanson, J.W., S.G. Ortman, and J. Lobo. 2017. "Urbanization and the division of labor in the Roman Empire”. Journal of the Royal Society Interface 20170367.

Heath, S. 2016. roman-amphitheaters [Github repository]. http://github.com/sfsheath/romanamphitheaters. Accessed 10th December 2018.

Hopkins, K. 1983. Death and Renewal. Sociological studies in Roman history volume 2. Cambridge: Cambridge University Press.

Humphrey, J.H. 1986. Roman Circuses: Arenas for chariot racing. Berkeley: University of California Press.

Kolendo, J. 1981. "La répartition des places aux spectacles et la stratification sociale dans l’Empire Romain". Ktema 6:301-15.

Laurence, R., S. Esmonde Cleary, G. Sears. 2011. The City in the Roman West, c. 250 BC-c. AD 250. Cambridge: Cambridge University Press. 
Mann, C. 2011. “Um keinen Kranz, um das Leben kämpfen wir!” Gladiatoren im Osten des römischen Reiches und die Frage der Romanisierung. Berlin: Vandenhoeck and Ruprecht.

Moore, J.D. 1996. "The Archaeology of plazas and the proxemics of ritual: Three Andean traditions". American Anthropologist 98.4:789-802.

Nelis-Clément, J., and J.-M. Roddaz. 2008. Le cirque romain et son image. Bordeaux: Ausonius.

Ortman, S.G., A.H.F. Cabaniss, J.O. Sturm, and L.M.A. Bettencourt. 2014. "The pre-history of urban scaling”. PLoS One 9.2. e87902.

Osanna, M. 2018. "Games, banquets, handouts, and the population of Pompeii as deduced from a new tomb inscription”. Journal of Roman Archaeology 31.1:310-22.

Packer, J.E., J. Burge, and M.C. Gagliardo. 2007. “Looking again at Pompey’s Theater: The 2005 excavation season”. American Journal of Archaeology 111.3:505-22.

Rawson, E. 1987. "Discrimina ordinum: The Lex Julia Theatralis". Papers of the British School at Rome 55:83-114. 
Robert, L. 1940. Les gladiateurs dans l'Orient grec. Paris: E. Champion.

Rose, P. 2005. "Spectators and spectator comfort in Roman entertainment buildings: A study in functional design”. Papers of the British School at Rome 73:99-130.

Sabbatini Tumolesi, P. 1980. Gladiatorum paria. Annunci di spettacoli gladiatorii a Pompei. Rome: Edizioni di storia e letteratura.

Schläpfer, M., L.M.A. Bettencourt, S. Grauwin, M. Raschke, R. Claxton, Z. Smoreda, G.B. West, and C. Ratti. 2014. "The scaling of human interactions with city size". Journal of The Royal Society Interface 20130789.

Sear, F. 2006. Roman Theatre: An architectural study. Oxford: Oxford University Press.

Sinner, A.G., and C. Carreras. 2019. "Methods of palaeodemography: The case of the Iberian oppida and Roman cities in north-east Spain". Oxford Journal of Archaeology 38.3:302-24. 
Smith, M.E. 2018. "Energized crowding and the generative role of settlement aggregation and urbanization". In Coming Together: Comparative approaches to population aggregation and early urbanization, edited by A. Gyucha, 37-58. Albany: State University of New York Press.

Veyne, P. 1976. Le pain et le cirque: sociologie historique d'un pluralisme politique. Paris: Seuil.

Welch, K. 2007. The Roman Amphitheater from its Origins to the Colosseum. Cambridge: Cambridge University Press.

Wheatley, D., and M. Gillings. 2002. Spatial Technology and Archaeology: The archaeological applications of GIS. London: Taylor and Francis.

Wiedemann, T.E.J. 1992. Emperors and Gladiators. London and New York: Routledge.

Wilson, A.I. 2011. "City sizes and urbanization in the Roman Empire”. In Settlement, Urbanization, and Population, edited by Bowman, A.K., and A.I. Wilson, 161-95. Oxford: Oxford University Press. 
Wilson Jones, M. 1993. “Designing amphitheaters”. Mitteilungen des Deutschen Archäologischen Instituts 100:391-441.

- 2009. "The setting out of amphitheaters; ellipse or oval? Questions answered and not answered". In Roman Amphitheaters and Spectacula: A $21^{\text {st }}$ century perspective, edited by T. Wilmot, 5-16. Oxford: Archaeopress.

Zuiderhoek, A. 2016. The Ancient City. Cambridge: Cambridge University Press.

$<$ A $>$ Endnotes

${ }^{1}$ Frank 1938; Duncan-Jones 1982, 262; Hanson 2016, 51; Hanson and Ortman 2017, 302-3.

${ }^{2}$ Laurence et al. 2011.

${ }^{3}$ Veyne 1976; Zuiderhoek 2016.

${ }^{4}$ Carter and Edmondson 2014, 549.

${ }^{5}$ Duncan-Jones 1982, 262; Laurence et al. 2011, 243; 263; 268; Sinner and Carreras 2019.

6 Tacitus, Annals, XIV, 17; Duncan-Jones 1982, 262; Laurence et al. 2011, 122; 253.

${ }^{7}$ Sabbatini Tumolesi 1980; Carter and Edmondson 2014, 545; Laurence et al. 2011, 268.

${ }^{8}$ Smith 2018, 48-51; table 2.3.

${ }^{9}$ Hanson et al. 2019. 
${ }^{10}$ Hansen 2006, 35-63; Wilson 2011; De Ligt 2012, 210-24; Hanson 2016, 49-74; Hanson and Ortman 2017.

${ }^{11}$ Bettencourt et al. 2007; Bettencourt 2013; Ortman et al. 2014; Hanson 2016, 32; Hanson and Ortman 2017; Hanson et al. 2017, 2019.

${ }^{12}$ Bettencourt 2014; Schläpfer et al. 2014.

${ }^{13}$ See Smith 2018 for an introduction to some of these ideas.

${ }^{14}$ Zuiderhoek 2017, 97.

${ }^{15}$ See Canuto and Yaeger 2000 for some discussion of these ideas in other contexts.

${ }^{16}$ Bettencourt 2014; Schläpfer et al. 2014.

${ }^{17}$ Hanson and Ortman 2017.

${ }^{18}$ Hanson and Ortman 2017.

${ }^{19}$ Bettencourt et al. 2010.

${ }^{20}$ Hanson 2016, 18-24.

${ }^{21}$ Hansen 2006, 35-63; Wilson 2011; De Ligt 2012, 210-24; Hanson 2016, 49-74; Hanson and Ortman 2017.

${ }^{22}$ Hanson 2016, 49-74.

${ }^{23}$ Hanson and Ortman 2017.

${ }^{24}$ Bettencourt 2013; Ortman, et al. 2014.

${ }^{25}$ Special note needs to be taken of Pompeii. As Osanna has shown in an important article, we might be able to come up with new evidence for the population of the site based on a newly discovered inscription from just outside the Porta Stabia, which records the donation of a banquet for 6,840 individuals on 456 dinning couches (each seating 15 individuals) to the people of Pompeii (Osanna 2018, 315-16). This leads him to suggest a total population of some 30,000, 
assuming the banquet was restricted to adult males. It seems more likely, however, that the recipients would have included both the residents of the city and its hinterland, in keeping with the ancient practice of treating the two as one unit, especially since this figure would suggest a population density of around 500 people per hectare for the whole site, which would be extremely large by comparative standards. We therefore follow earlier work in using the size of the inhabited area and the densification effect discussed above to estimate the population of the site and obtain a figure almost identical to earlier estimates based on the available stock of housing (Hanson and Ortman 2017, 321; Flohr 2017, 53-68).

${ }^{26}$ Carter and Edmondson 2014, 537.

${ }^{27}$ For some of the rich discussion about the architectural design and various social, cultural, religious, and political aspects of theaters and amphitheaters in the last few decades see Auguet 1972; Hopkins 1983, 1-30; Golvin 1988; Beacham 1991; Wiedemann 1992; Gros 1996, $272-$ 307; 317-45; Beacham 1999; Bomgardner 2000; Sear 2006, 1-36; Welch 2007; Fagan 2011;

Laurence et al. 2011, 231-84; Zuiderhoek 2016, 65; 86; 96; 146.

${ }^{28}$ Hanson et al. 2019.

${ }^{29}$ Kolendo 1981; Rawson 1987; Rose 2005, 100-2; Carter and Edmondson 2014, 547-49.

${ }^{30}$ Rose 2005, 102-14.

${ }^{31}$ Rose 2005, 100-1.

${ }^{32}$ Hanson 2016, 77.

${ }^{33}$ Sear 2006.

${ }^{34}$ Golvin 1988; Bomgardner 2000.

35 https://github.com/sfsheath/roman-amphitheaters (accessed 10th December 2018).

${ }^{36}$ Sear 2006, 98-100. 
${ }^{37}$ Humphrey 1986; Nelis-Clément and Roddaz 2008.

${ }^{38}$ For discussion of the evidence for gladiators in the east see Robert 1940 and, more recently, Mann 2011. For discussion of modifications to the structures themselves see Golvin 1988, 237-

49; Welch 2003, 164-78; and Sear 2006, 43-44.

${ }^{39}$ Rose 2005, 115-16.

${ }^{40}$ Rose 2005, 115; table 2.

${ }^{41}$ Rose 2005, 116; table 3.

${ }^{42}$ Wilson Jones 1993, 394-401; 2009, 5-16.

${ }^{43}$ Rose 2005, 115.

${ }^{44}$ Golvin 1988, 380-81; Bomgardner 2000, table 1.2 n. 40; Rose 2005, 115.

${ }^{45}$ Rose 2005, 115.

${ }^{46}$ Rose 2005, 114-15.

${ }^{47}$ Vitruvius, Ten Books on Architecture, V, 6, 3-4; Rose 2005, 114.

${ }^{48}$ Rose 2005, 115.

49 Tacitus, Annals, IV, 62.

${ }^{50}$ Rose 2005, table A.

${ }^{51}$ Gagliardo and Packer 2006; Packer et al. 2007; Carandini 2017.

${ }^{52}$ Bettencourt et al. 2010.

${ }^{53}$ Hanson 2016, 83.

54 Wheatley and Gillings 2002; Conolly and Lake 2006; Hanson 2016, 89-90.

55 Wheatley and Gillings 2002; Conolly and Lake 2006, Hanson 2016, 88.

${ }^{56}$ http://odedgalor.virb.com/caloric-suitability-index (accessed 7th January 2019); Galor and Özak 2015, 2016; Galor et al. 2016. 
${ }^{57}$ Hanson 2016.

${ }^{58}$ Hanson 2016, 79.

${ }^{59}$ These relationships were assessed using a common form of regression, namely ordinary leastsquares regression, and $\log$-transformed data. This is feasible because $C=c_{0} N^{\beta}$ and $\log C=$ $\beta \log N+\log c_{0}$ are equivalent expressions, meaning that one can estimate the exponent and prefactor of the power function by estimating the slope and intercept of the linear function fit to the $\log$-transformed values.

${ }^{60}$ Duncan-Jones 1982, 262; Laurence et al. 2011, 243; 263; 268; Sinner and Carreras 2019.

${ }^{61}$ Benario 1981, 255; Rose 2005, Table A.

${ }^{62}$ Rose 2005, 122.

${ }^{63}$ See Moore 1996 and Bowser and Patton 2004 for additional applications of this idea.

${ }^{64}$ Bairoch 1988, table 15.1. 